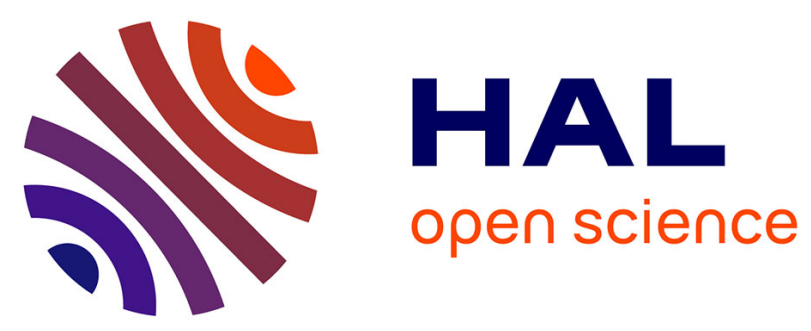

\title{
Sensitivity of Main Polarimetric Parameters of Multifrequency Polarimetric SAR Data to Soil Moisture and Surface Roughness Over Bare Agricultural Soils
}

Nicolas Baghdadi, Pascale Dubois-Fernandez, Xavier Dupuis, Mehrez Zribi

\section{- To cite this version:}

Nicolas Baghdadi, Pascale Dubois-Fernandez, Xavier Dupuis, Mehrez Zribi. Sensitivity of Main Polarimetric Parameters of Multifrequency Polarimetric SAR Data to Soil Moisture and Surface Roughness Over Bare Agricultural Soils. IEEE Geoscience and Remote Sensing Letters, 2013, 10 (4), pp.731-735. 10.1109/LGRS.2012.2220333 . hal-00910968

\section{HAL Id: hal-00910968 https://hal.science/hal-00910968}

Submitted on 28 Nov 2013

HAL is a multi-disciplinary open access archive for the deposit and dissemination of scientific research documents, whether they are published or not. The documents may come from teaching and research institutions in France or abroad, or from public or private research centers.
L'archive ouverte pluridisciplinaire HAL, est destinée au dépôt et à la diffusion de documents scientifiques de niveau recherche, publiés ou non, émanant des établissements d'enseignement et de recherche français ou étrangers, des laboratoires publics ou privés. 


\title{
Sensitivity of main polarimetric parameters of multi-frequency polarimetric SAR data to soil moisture and surface roughness over bare agricultural soils
}

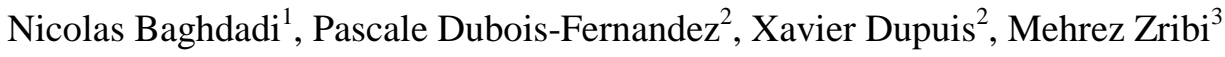 \\ ${ }^{1}$ Irstea, UMR TETIS, 500 rue François Breton, 34093 Montpellier cedex 5, France \\ ${ }^{2}$ ONERA / DEMR, Centre de Salon de Provence, 13661 Salon-Air, France \\ ${ }^{3}$ CESBIO, 18 av. Edouard Belin, bpi 2801, 31401 Toulouse cedex 9, France \\ E-mail: nicolas.baghdadi@teledetection.fr \\ Tel.: 334675487 24; Fax: 33467548700
}

\begin{abstract}
The potential of polarimetric Synthetic Aperture Radar (SAR) data for the soil surface characterization of bare agricultural soils was investigated in using airborne and spaceborne data acquired by RAMSES, SETHI and RADARSAT-2 sensors over several study sites in France. Fully polarimetric data at X-, C-, L-, P-, and UHF-band were compared. The results show that the main polarimetric parameters studied (entropy, $\alpha$ angle, and anisotropy) are not very sensitive to the variation of the soil surface parameters. Low correlations are observed between the polarimetric parameters and the soil parameters (moisture content and surface roughness). Thus, the polarimetric parameters are not very relevant to the characterization of the soil surface over bare agricultural areas.
\end{abstract}

Index Terms - Multi-frequency Polarimetric SAR data, bare agricultural soils, soil moisture, surface roughness.

\section{INTRODUCTION}

$\mathrm{T}$ he Synthetic Aperture Radar (SAR) return signal over bare soils is affected mainly by the soil roughness and its dielectric constant ([1]). Numerous researches have shown that SAR sensors have a high potential to measure the surface soil moisture (e.g. [2]-[7]).

The benefits of radar polarimetry for the characterization soil moisture and surface roughness have been investigated in only few studies ([8]-[12]). Hajnsek et al. ([11]) proposed a method based on the small perturbation model (SPM) for the inversion of the fully polarimetric airborne L-band SAR data. The surface roughness was estimated directly from the anisotropy values and the dielectric constant from the diagram of entropy/ $\alpha$ angle. However, the SPM model is valid for soils with surface roughness small compared to the radar wavelength ( $k r m s<0.3$, where $k$ is the radar wave number and $r m s$ is the root mean square surface height). The typical rmsvalues of the agricultural bare soils range $(0.5$ to $4.5 \mathrm{~cm})$ largely exceed the SPM validity domain for SAR data at high radar frequencies ( $\mathrm{X}$ and $\mathrm{C}$ bands). At L-band $(\sim 1.25 \mathrm{GHz}$; $\left.k=0.26 \mathrm{~cm}^{-1}\right)$, this approach is not applicable in the case of rough soils (validity domain).

Baghdadi et al. ([13]) analyzed the sensitivity of C-band polarimetric SAR parameters to the soil moisture and surface roughness over bare agricultural fields. Results showed that the polarimetric parameters do not lead to a direct estimate of soil parameters, but they could help to improve the inversion approaches by adding a priori information. Indeed, the polarimetric parameter $\alpha$ angle could be used to discriminate two soil moisture classes (very wet soils and the remainder), while the anisotropy could be used to separate the smooth soils from the other soils.
The aim of this study is to investigate the sensitivity of polarimetric parameters to soil parameters (soil moisture and surface roughness) using multi-frequency and polarimetric SAR data (X, C, L, P, UHF bands). The polarimetric parameters: entropy, $\alpha$ angle and anisotropy obtained from the polarimetric decomposition theorem are used for soil surface characterization. Section 2 provides a description of study sites and available data set. The polarimetric parameters analysis is shown in Section 3, and finally, Section 4 presents the main conclusions.

\section{EXPERIMENTAL DATA}

\section{A. Study sites}

A database composed of fully polarimetric acquisitions from both airborne, spaceborne sensors and ground measurements over numerous flat agricultural study sites in France have been used (Figure 1, Table 1). The study sites are agricultural landscape composed mostly of bare soils, wheat fields, vineyards, grasslands, forest, and orchards of various fruit trees:

- Orgeval site "Org": located to the East of Paris (long. $3^{\circ} 07^{\prime} \mathrm{E}$, lat. $\left.48^{\circ} 51^{\prime} \mathrm{N}\right)$. Soil composition is about $78 \%$ silt, $17 \%$ clay, and $5 \%$ sand.

- Bordeaux site "Bor": located in the southwest of France (long. $0^{\circ} 50^{\prime} \mathrm{W}$, lat. $45^{\circ} 17^{\prime} \mathrm{N}$ ). The soil is composed of about $19 \%$ silt, $29 \%$ clay, and $51 \%$ sand.

- Thau site "Thau": located near Montpellier in the South of France (long. $03^{\circ} 40^{\prime} \mathrm{E}$, lat. $43^{\circ} 30^{\prime} \mathrm{N}$ ). Soil composition is about $52 \%$ silt, $35 \%$ clay, and $12 \%$ sand.

- Garons site "Gar": located near Nîmes in the South of France (long. $04^{\circ} 23^{\prime} \mathrm{E}$, lat. $43^{\circ} 45^{\prime} \mathrm{N}$ ). Soil composition is 
54\% silt, $40 \%$ clay, and $6 \%$ sand. The soil is stony.

- Avignon site "Avi": located in the south of France (long. $4^{\circ} 53^{\prime} \mathrm{E}$ and lat. $43^{\circ} 55^{\prime} \mathrm{N}$ ). The soil is composed of about $53.0 \%$ silt, $31.6 \%$ clay and $15.4 \%$ sand.

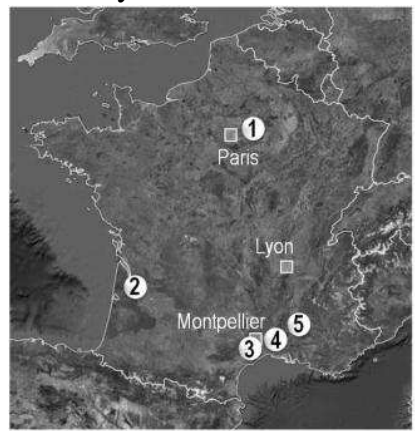

Fig. 1. Location of study sites. (1) Orgeval, (2) Bordeaux, (3) Thau, (4) Garons, (5) Avignon.

\section{B. Fully polarimetric data description}

Airborne and spaceborne fully polarimetric data were acquired on study sites. Data set contains SAR images in X, C, L, $\mathrm{P}$ and UHF bands (Table 1):

- Orgeval: Four RADARSAT-2 images (RS2) were acquired (C-band) in polarimetric mode with spatial resolution of approximately $5 \mathrm{~m}$ and incidence angles of $20^{\circ}, 25^{\circ}$, and $40^{\circ}$. These images correspond to March 2009 and April 2010. Moreover, one PALSAR/ALOS image was also acquired (L-band) with an incidence angle of about $20^{\circ}$ and a spatial resolution about $10 \mathrm{~m}$.

- Bordeaux: Fully polarimetric L- and P-bands radar data were acquired by the airborne RAMSES SAR ([14]) from the French Aerospace Research Center (ONERA) on January 21, 2004. The resolution of the SAR images in range and azimuth was $1 \mathrm{~m}$ for $\mathrm{L}$ band and $2.5 \mathrm{~m}$ for $\mathrm{P}$ band.

- Thau: Seven polarimetric RADARSAT-2 images were acquired between November 2010 and March 2011. These images have spatial resolutions of approximately 7 $\mathrm{m}$ and incidence angles of $34^{\circ}, 45^{\circ}$, and $47^{\circ}$.

- Garons: Fully polarimetric radar data were acquired by the new ONERA multispectral airborne SAR system SETHI ([15]). SAR images were acquired in June 2009 at L-band, and in October 2011 at both L- and UHF-bands. The spatial resolution was about $0.75 \mathrm{~m}$.

- Avignon: Fully polarimetric X-band radar data were acquired by the airborne RAMSES SAR on March 20, 2002. The spatial resolution was $0.66 \mathrm{~m}$.

The PolSARPro v4.2.0 software (http://earth.eo.esa.int/polsarpro/) was used to process the polarimetric SAR data. The three main polarimetric parameters, entropy $(H), \alpha$ angle, and anisotropy $(A)$ were calculated to analyze their behaviour with the soil surface parameters (moisture content and surface roughness). These parameters are computed by averaging several neighbouring pixels using a sliding window. For a correct retrieval of physical information, a 7x7 boxcar filter was applied to the RADARSAT-2 and PALSAR single-look complex data
([16],[17]). For RAMSES and SETHI data, a window of $15 \times 15$ was used.

TABLE I

CHARACTERISTICS OF THE DATASET USED IN THIS STUDY. MV IS THE SOIL MOISTURE, K IS THE RADAR WAVE NUMBER AND RMS IS THE ROOT MEAN SQUARE SURFACE HEIGHT OF SOIL SURFACE ROUGHNESS.

\begin{tabular}{|c|c|c|c|c|c|c|c|}
\hline Site & Year & Sensor & $\begin{array}{c}\text { Radar } \\
\text { freq. } \\
(\mathbf{G H z})\end{array}$ & $\begin{array}{c}\text { Incidence } \\
\text { angle } \boldsymbol{\theta}\left({ }^{(}\right)\end{array}$ & $\begin{array}{c}\text { Number } \\
\text { of fields }\end{array}$ & $\begin{array}{c}\boldsymbol{m} \boldsymbol{v}(\%) \\
{[\mathbf{m i n}-\mathbf{m a x}]}\end{array}$ & $\begin{array}{c}\boldsymbol{k} \text { rms } \\
{[\mathbf{m i n} \text { - max }]}\end{array}$ \\
\hline Org & $2009-2010$ & RS2 & 5.4 & $20-25-40-45$ & 31 & {$[12.7-39.0]$} & {$[0.54-3.19]$} \\
& 2009 & PALSAR & 1.27 & 20 & 8 & {$[16.8-27.6]$} & {$[0.33-0.68]$} \\
\hline Thau & $2010-2011$ & RS2 & 5.4 & $34-45-47$ & 77 & {$[9.0-45.7]$} & {$[1.09-4.41]$} \\
\hline Bor & 2004 & RAMSES & 1.6 & 51 & 4 & {$[26.9-46.9]$} & {$[0.26-0.52]$} \\
& & & 0.435 & 51 & 4 & {$[26.9-46.9]$} & {$[0.12-0.26]$} \\
\hline Gar & 2009 & SETHI & 1.325 & 42 & 10 & {$[3.5-14.9]$} & {$[0.33-1.42]$} \\
& 2011 & & 1.325 & 43 & 4 & {$[2.8-9.0]$} & {$[0.16-0.43]$} \\
& 2011 & & 0.360 & 42 & 4 & {$[2.8-9.0]$} & {$[0.04-0.12]$} \\
\hline Avi & 2002 & RAMSES & 9.6 & 27 & 4 & {$[18.2-25.5]$} & {$[1.60-4.80]$} \\
\hline
\end{tabular}

\section{Field data}

In-situ measurements of soil moisture and surface roughness were conducted simultaneously with the SAR acquisitions on several reference fields at least one hectare. Only bare soils or soils with few short herbs were selected.

Soil roughness measurements were made using $1 \mathrm{~m}$ or $2 \mathrm{~m}$ long needle profilometers with $2 \mathrm{~cm}$ sampling intervals. From ten roughness profiles measured on each reference field, the root mean square $(r m s)$ surface height and the correlation length were calculated using the mean of all correlation functions. The rms surface heights range from 0.48 to $5.12 \mathrm{~cm}$ (Table 1), and the correlation length not used in this study varies from 1.67 to $8.63 \mathrm{~cm}$.

Soil moisture measurements were collected from the top 5 $\mathrm{cm}$ of soil in using a calibrated TDR (Time Domain Reflectometry) probe or the gravimetric method. The volumetric water content at field scale was assumed to be equal to the mean value estimated from several samples (20 to 40 measurements per field). The soil moistures $(m v)$ range from 2.8 to $46.9 \%$.

The average $\alpha$ angle, $H$ and $A$ were then calculated for each reference field.

\section{POLARIMETRIC SENSITIVITY}

\section{A. Polarimetric parameters Description}

Using the eigenvectors and eigenvalues obtained from the decomposition of coherency matrix $T$, three main polarimetric parameters are used ([18]): entropy $(H)$, alpha angle $(\alpha)$, and anisotropy $(A)$.

The entropy $H$ represents the randomness of scattering mechanisms. Low entropy $(H \sim 0)$ indicates a single scattering mechanism while high entropy $(H \sim 1)$ indicates a random mixture of scattering mechanisms and a depolarizing target:

$$
H=-\sum_{i=1}^{3} P_{i} \cdot \log _{3}\left(P_{i}\right) \quad ; \quad P_{i}=\lambda_{i} / \sum_{j=1}^{3} \lambda_{j}
$$

where $\lambda_{i}$ are the eigenvalues of $T\left(\lambda_{1} \geq \lambda_{2} \geq \lambda_{3} \geq 0\right)$.

The angle $\alpha$ represents the mean scattering mechanism and it is calculated from the eigenvectors and eigenvalues of $T$.

$$
\alpha=\sum_{i=1}^{3} \alpha_{i} P_{i}
$$


where $\alpha_{i}$ are the scattering angles corresponding to the three eigenvalues. Low values $\left(\alpha=0^{\circ}\right)$ indicates a surface scattering, $\alpha=45^{\circ}$ indicates a volume scattering, and $\alpha=90^{\circ}$ indicates a double bounce scattering:

The anisotropy $A$ is defined as the relative importance of the secondary scattering mechanisms (second and third eigenvalues). $A$ becomes 0 if both of these secondary scattering mechanisms are of equal proportion, while the larger values of $A(A=1)$ indicates that the third mechanism is weak compared to the second one:

$$
A=\frac{\lambda_{2}-\lambda_{3}}{\lambda_{2}+\lambda_{3}}
$$

\section{Polarimetric parameters analysis}

\section{1) $\alpha$-angle}

Figure 2 displays the dependence of $\alpha$ angle for the whole of the data set (X to UHF bands) with respect to soil moisture $(m v)$, surface roughness $(k r m s)$ and incidence angle. Results indicate that the $\alpha$-angle is independent of the radar frequency (Fig. 2a). Moreover, the $\alpha$-angle is constant for $m v$ between $5 \%$ and $25-30 \%$, and increases slightly for $m v$ values between $30 \%$ and $47 \%$. The observed $\alpha$-values correspond mainly to surface scattering ( $\alpha$ lower than $45^{\circ}$ ), except for data in UHF band where $\alpha$-angle is about $45^{\circ}$. The high penetration of the radar wave in the UHF band for dry soil conditions $(m v<5 \%)$ explains this volume scattering in this radar wavelength. Moreover, such an alpha angle could result from either volume scattering or noise dominated scattering. In this dataset, the noise floor was estimated to be at least $3 \mathrm{~dB}$ lower than the HV return, indicating that the most likely explanation for a $45^{\circ}$ alpha angle is volume scattering.

Figure $2 b$ shows that the $\alpha$-angle is independent of $k$ rms. Indeed, $\alpha$-angle is constant with $k$ rms over the full dataset for $m v<25 \%$ (mainly X, C, L and UHF bands). For $m v>25 \%$ (mainly $\mathrm{C}, \mathrm{L}$ and $\mathrm{P}$ bands), the $\alpha$-angle is also constant with $k$ $r m s$ except for data corresponding to $k$ rms higher than 2 where $\alpha$-angle is slightly lower than the values observed for lower $k \mathrm{rms}$. Note that they correspond mainly to the Orgeval data set acquired at low incidence angles of $20^{\circ}-25^{\circ}$ and Cband.

Finally, $\alpha$-angle depends slightly of the radar incidence angle (Fig. 2c). Indeed, $\alpha$-angle increases slightly when the incidence angle increases. The lower $\alpha$-values correspond to Orgeval dataset acquired at C-band and incidence angles of $20^{\circ}-25^{\circ}$ (Fig. 2a). Moreover, $\alpha$-angle seems less to depend on the incidence angle for $m v<25 \%$ than for $m v>25 \%$, except for UHF data (volume scattering) and one reference field in Pband (soil moisture near 50\%) where $\alpha$-angle is higher than $40^{\circ}$. Hajnsek et al. ([11]) confirmed that the dependence between $\alpha$-angle and incidence angle is higher for $m v>25 \%$ than for $m v<25 \%$.

Allain et al. ([8]) suggested inversion models based on the Integral Equation Model for estimating soil moisture and surface roughness. For high frequency bands (C to K), they propose the use of $\alpha$-angle in the inversion process of soil moisture. Moreover, their results show that the estimation of surface roughness is not possible in using only high frequency bands and that SAR data acquired at low frequency band (P to
S) are also necessary. However, a low frequency alone will allow estimating both soil moisture and surface roughness in using the three polarimetric descriptors: anisotropy, $\alpha$-angle and the eigenvalue relative difference (ERD). Our results show limited contribution of $\alpha$-angle for the soil moisture estimation. Moreover, our analysis showed that the single-bounce Eigenvalue Relative Difference (SERD) is constant with $k \mathrm{rms}$. The dependence between $\alpha$-angle and $m v$ shows that $\alpha$-angle is constant with $m v$ for $m v<30 \%$ and decreases slightly with $m v$ for $m v>30 \%$. The double-bounce Eigenvalue Relative Difference (DERD) is almost constant with $m v$ and decreases slightly with $k r m s$ for $k r m s$ values lower than 1 and became constant afterwards. These parameters, as suggested in Baghdadi et al. ([13]), could not be used easily for the estimation of soil parameters.

A comparison between the results of Hajnsek et al. [11] and our dataset was carried out using only the data of our dataset within the validity domain of the small perturbation model (SPM) $(k r m s<0.3)$ and which have a low noise level ( $\mathrm{L}$ and $\mathrm{P}$ bands). For incidence angles $(\theta)$ of $42^{\circ}-43^{\circ}$ and $51^{\circ}$, the $\alpha-$ angle values simulated in [11] are slightly lower by $7^{\circ}$ than the $\alpha$-angle of our real dataset. With low incidence angle $\left(20^{\circ}\right)$, high underestimation of the $\alpha$-angle was observed by the SPM ( $\alpha=5^{\circ}$ from SPM and $25^{\circ}$ from our real data, for $m v=20 \%$ ).

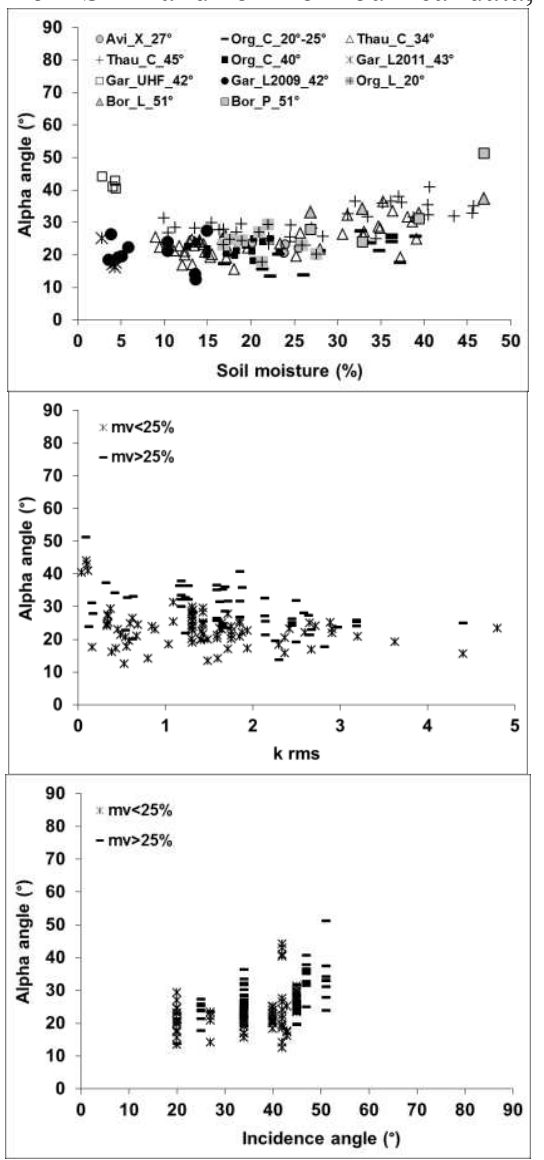

(a)

Fig. 2. $\alpha$-angle versus soil moisture (a), surface roughness (b), and incidence angle (c). The ranges of $m v$ (in \%) are [18.2-25.5], [9.0-39.0], [2.8-46.9], $[26.9,46.9]$, and $[2.8-9.0]$ for X, C, L, P and UHF bands respectively.

\section{2) Entropy}

The comparison between the entropy values for the data set in $\mathrm{C}$ and $\mathrm{X}$ bands shows that the entropy does not change with 
the radar frequency for a same incidence angle and a same soil moisture value (see Avi_X_27 $7^{\circ}$ Org_C_20 ${ }^{\circ} \_25^{\circ}$, and Thau_C_34 ${ }^{\circ}$; Fig. 3a). Entropy decreases slightly with the soil moisture for $m v<25 \%$ and increases then quickly with $m v$ for $m v>25 \%$ (Fig. 3a). Moreover, entropy increases slightly with the incidence angle (see Thau_C_45 $5^{\circ}$ and Thau_C_34 ; Fig. 3a). For higher radar wavelengths (L, P, and UHF bands), Figure $3 b$ does not show a clear behaviour of entropy in function of $m v$. For a given soil moisture range, the entropy values are of the same order for all SAR frequencies available in this study, except for UHF data where high entropy values are observed (Figs $3 \mathrm{a}$ and $3 \mathrm{~b}$ ). These UHF data correspond to fields with volume scattering (very dry soil, penetration effect). In this case, the polarimetric decomposition identifies three mechanisms of similar strength, resulting in high entropy.

Moreover, Figure $3 \mathrm{c}$ shows that the entropy does not seem to depend of $m v$ for $k r m s<1$ (case of high radar wavelengths). For $k r m s>1$ ( $\mathrm{C}$ and $\mathrm{X}$ bands), entropy is slightly higher for $m v>25 \%$ than that for $m v<25 \%$ (Fig. 3c). Finally, the data set do not allow determining the behaviour of entropy with $k$ rms. The first results of this study show that the entropy does not seem to depend of $k$ rms (Fig. 3c).

The entropy values encountered in Hajnsek et al. [11] (maximum value for $H$ is 0.45 ) are lower than those of our real dataset ( $H$ between 0.4 and 0.8 ).

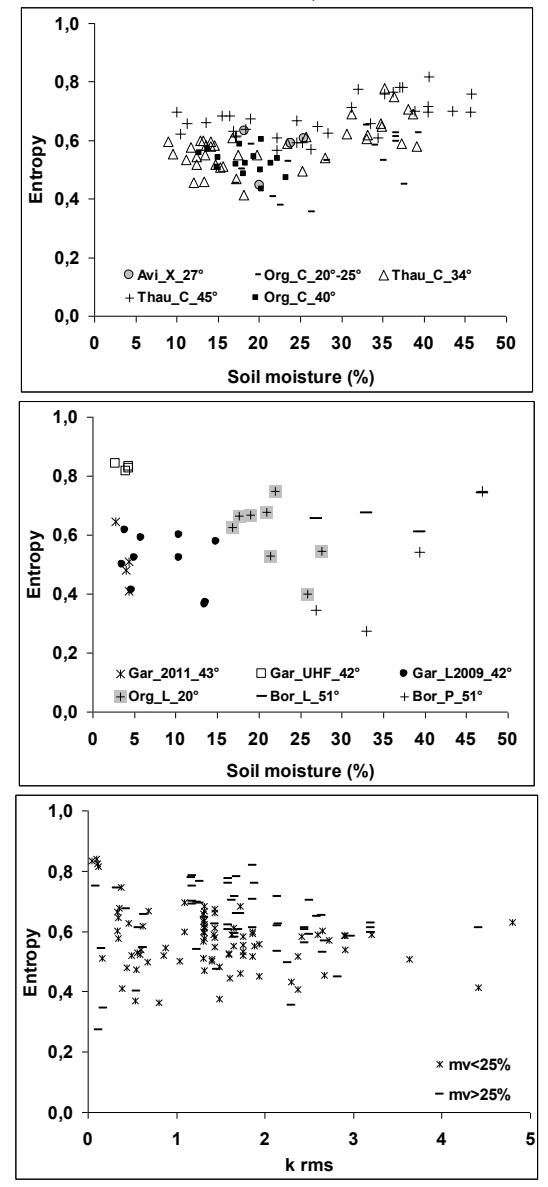

Fig. 3. Entropy versus soil moisture (a), and surface roughness (b).

\section{3) Anisotropy}

The behaviour of the anisotropy depends of the radar frequency but does not seem dependent of the radar incidence angle (Fig. 4). Indeed, the anisotropy stays constant in C and $\mathrm{X}$ bands when the soil moisture increases between $10 \%$ and $45 \%$ (Fig. 4a). For L, P and UHF bands, the anisotropy decreases for soil moisture between 3\% and 10\% and next increases for $m v$ between $10 \%$ and $47 \%$ (Fig. 4b). Thus, a same anisotropy value could correspond to two values of $m v$.

The anisotropy is also independent of $k r m s$ for $k r m s>1$ (Fig. 4c). Moreover, $A$ seem independent of both $m v$ and radar frequency for $k r m s>1$ (Fig. 4c). For $k r m s$ lower than 1, the anisotropy decreases more strongly with $k \mathrm{rms}$ for $m v>25 \%$ than for $m v<25 \%$ (from 0.6 to 0.25 for $m v>25 \%$ and from 0.45 to 0.25 for $m v<25 \%$ ).

In Hajnsek et al. [11], the anisotropy varies from 0.9 to 0.2 for $k r m s$ between 0.1 and 1 . This variation of $A$ is lower with our real dataset ( $A$ between 0.6 and 0.35 ).

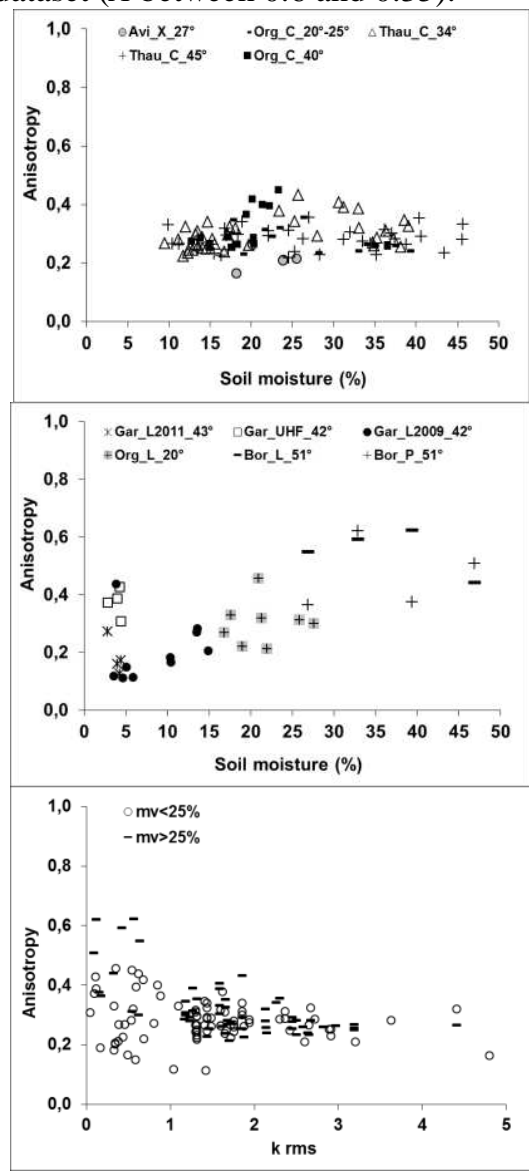

(a)

Fig. 4. Anisotropy versus soil moisture in $\mathrm{C}$ and $\mathrm{X}$ bands (a), soil moisture in L, P and UHF bands (b), and surface roughness $k r m s$ (c).

\section{4) $H / \alpha$ and $H / A$ planes}

The distribution of data in the $\mathrm{H} / \mathrm{A}$ and $\mathrm{H} / \alpha$ planes is shown in Figure 5. The low-medium entropy values $(<0.8)$ and low $\alpha$ angle values $\left(<40^{\circ}\right)$ correspond to the present of one dominant scattering mechanism, which is the surface scattering. For UHF data, the high entropy values (about 0.85 ) and $\alpha$-angle values around $45^{\circ}$ are the consequence of the volume scattering mechanisms and depolarizing effects due to the penetration of the radar wave in the soil at higher wavelengths and dry soil conditions (Fig. 4a).

The H/A plane show a majority of data with low-medium entropies and low anisotropies (Fig. 4b). These data 
corresponds to the presence of a single dominant scattering process. However, some points have low-medium entropies and high anisotropies. They correspond to data acquired in $\mathrm{L}$ and $\mathrm{P}$ bands, and in very wet soil conditions (Bordeaux, $m v>30 \%$ ). These points illustrate the presence of two scattering mechanisms with a dominant process and a second one which is not negligible. UHF data with high entropy and low anisotropy corresponds to a random scattering process, resulting probably from a very weak backscatter from the bare surfaces, close to the noise floor of the system. Indeed, when the backscattering levels are close to the noise floor, the radar response has two major contributions: the ground return and the noise return. The noise return has an entropy of 1 . Therefore, the effect of the noise on the radar return will be an increase in the entropy and a drop in the anisotropy (equivalent levels for the second and the third eigenvalues).
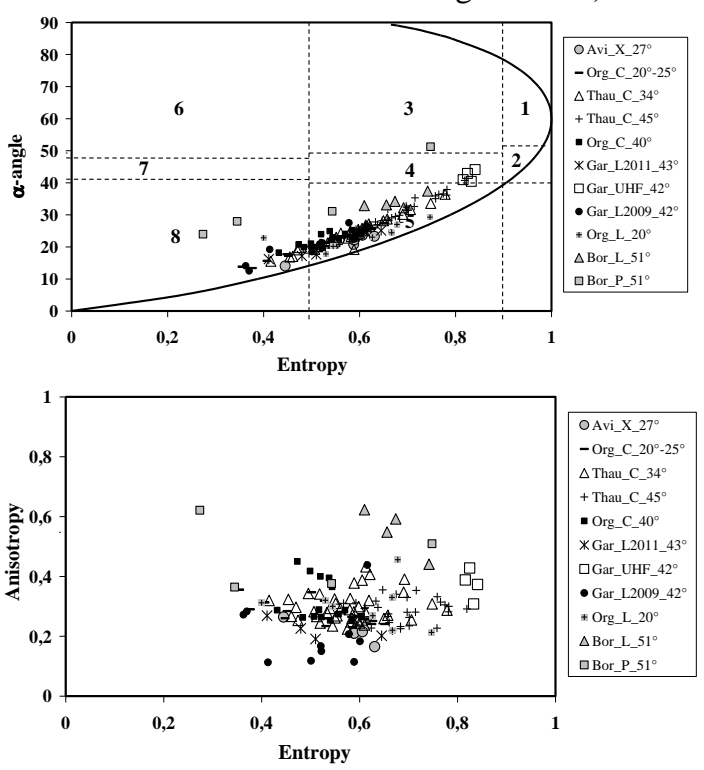

Fig. 5. Distribution of SAR data for reference fields in the $H / \alpha$ and $H / A$ planes. $\mathrm{H} / \alpha$ is divided into eight zones.

\section{CONCLUSIONS}

This study examined the sensitivity of multi-frequency (X, $\mathrm{C}, \mathrm{L}, \mathrm{P}$ and UHF bands) polarimetric SAR data to soil moisture and surface roughness over bare agricultural soils. The results of the study show that the last spatial SAR sensors functioning in polarimetric mode (RADARDAT-2 and PALSAR) in complement to airborne sensors RAMSES and SETHI did not demonstrated an important interest in the use of polarimetric parameters in order to estimate surface roughness and soil moisture. However, several studies showed that the polarimetric parameters could be useful in the classification of land use and land cover.

\section{ACKNOWLEDGMENT}

This work was supported by the Irstea (National Research Institute of Science and Technology for Environment and Agriculture), the ONERA (French Aerospace Research Centre) in the framework of the ENVIRO project, and the FP7 CLIMB project (Climate-induced changes on the hydrology of Mediterranean Basins). The authors wish to thank the CSA
(Canadian Space Agency) for kindly providing the RADARSAT-2 data (SOAR-E Project 5032).

\section{REFERENCES}

[1] A. K. Fung, "Microwave Scattering and Emission Models and their Applications," Artech House, Inc., Boston, London, 573 pages, 1994.

[2] J. Alvarez-Mozos, J. Casali, M. Gonzalez-Audicana, and N.E.C. Verhoest, "Assessment of the operational applicability of RADARSAT1 data for surface soil moisture estimation," IEEE Transactions on Geoscience and Remote Sensing, vol. 44, 913-924, 2006.

[3] N. Baghdadi, N. Holah, and M. Zribi, "Soil moisture estimation using multi-incidence and multi-polarization ASAR SAR data," International Journal of Remote Sensing, 27(10): 1907-1920, 2006.

[4] H. Lievens, N. E. C. Verhoest, E. De Keyser, H. Vernieuwe, P. Matgen, J. Álvarez-Mozos, and B. De Baets, "Effective roughness modelling as a tool for soil moisture retrieval from C- and L-band SAR," Hydrology and Earth System Sciences, 15, 2011, pp. 151-162, doi:10.5194/hess-15-151-2011.

[5] F. Mattia, G. Satalino, V.R.N. Pauwels, and A. Loew, " Soil moisture retrieval through a merging of multi-temporal L-band SAR data and hydrologic modeling," Hydrological and Earth System Sciences, vol. 13, issue 3, pp. 343-356, 2009.

[6] N.E.C Verhoest, H. Lievens, W. Wagner, J. Álvarez-Mozos, S. Moran, and F. Mattia, "On the Soil Roughness Parameterization Problem in Soil Moisture Retrieval of Bare Surfaces from Synthetic Aperture Radar," Sensors, vol. 8, pp. 4213-4248, DOI: 10.3390/s8074213, 2008.

[7] M. Zribi, and M. Dechambre, "A new empirical model to retrieve soil moisture and roughness from C-band radar data," Remote Sensing of Environment, vol. 84, pp. 42-52, 2002.

[8] S. Allain, L. Ferro-Famil, and E. Pottier, "Two novel surface model based inversion algorithms using multi-frequency polSAR data," Proceedings IGARSS 2004, Anchorage, AK, USA, September 20-24, 2004.

[9] S. Allain, L. Ferro-Famil, and E. Pottier, "A polarimetric classification from Polsar data using SERD/DERD parameters," Proceedings EUSAR, Dresden, Germany, May 16-18, 2006.

[10] P. Dubois, J.J. van Zyl, and T. Engman, "An empirical Soil Moisture Estimation Algorithm Using Imaging Radars," IEEE Transactions on Geoscience and Remote Sensing, vol. 33, no. 4, pp. 915-926, 1995.

[11] I. Hajnsek, E. Pottier, and S. Cloude, "Inversion of surface parameters from polarimetric SAR," IEEE Transactions on Geoscience and Remote Sensing, 41(4), pp. 727-744, 2003.

[12] Y. Oh, K. Sarabandi, and F.T. Ulaby, "An empirical model and an inversion technique for radar scattering from bare soil surfaces," Transactions on Geoscience and Remote Sensing, vol. 30, pp. 370-382, 1992.

[13] N. Baghdadi, R. Cresson, E. Pottier, M. Aubert, M. Zribi, A. Jacome, and S. Benabdallah, "A potential use for the C-band polarimetric SAR parameters to characterise the soil surface over bare agriculture fields," IEEE Transactions on Geoscience and Remote Sensing, in press, 2012.

[14] Dubois-Fernandez, O. Ruault du Plessis, B. Vaizan, X. Dupuis, H. Cantalloube, C. Coulombeix, C. Tintin-Schneider, Ph. Dreuillet, J.M. Boutry et al., "The ONERA RAMSES SAR system," International Geoscience and Remote Sensing Symposium IGARSSO2, Toronto, Canada, 24-28 June 2002 (Piscataway, NJ: IEEE), CDRom.

[15] G. Bonin, P. Dubois-Fernandez, Ph. Dreuillet, O. Ruault du Plessis, S. Angelliaume, H. Cantalloube, H. Oriot, and C. Coulombeix, "The new ONERA multispectral Airbrone SAR system in 2009," Radar Conference, 2009 IEEE, pp. 1-3, 4-8 May 2009, Pasadena, DOI: 10.1109/RADAR.2009.4976985

[16] C. Lopez-Martinez, and E. Pottier, "Study of the speckle noise effects over the eigen decomposition of polarimetric SAR data," Proceedings of the $2^{\text {nd }}$ international workshop on applications of polarimetry and polarimetric interferometry. Frascati, Italy, 17-21 January 2005 POLinSAR05 (ESRIN, ESA), CDRom.

[17] J. S. Lee, T. L. Ainsworth, J. P. Kelly, and C. Lopez-Martinez, "Evaluation and bias removal of multilook effect on Entropy/Alpha/Anisotropy in polarimetric SAR decomposition," IEEE Transactions on Geoscience and Remote Sensing, 46(10), pp. 30393052, 2008. 
[18] Cloude, S.R. and E. Pottier, "A review of target decomposition theorems in radar polarimetry," IEEE Transactions on Geoscience and Remote Sensing, vol. 34, no. 2, pp. 498-518, 1996.
Manuscript received June xx, 2012; revised xx xx, 2012. Corresponding author: N. Baghdadi (e-mail: nicolas.baghdadi@teledetection.f 